\title{
Kausalitas dalam Novel Lelaki Harimau Karya Eka Kurniawan
}

Ibnu Yustiya Ramadhan

Airlangga University, Surabaya, Indonesia

Email: ibnu.yustiya.ramadhan-2018@fib.unair.ac.id

\begin{tabular}{l}
\hline \hline Article Info \\
\hline Article history: \\
Submitted Jan 20, 2020 \\
Revised Feb 19, 2020 \\
Accepted April 20, 2020 \\
Published April 30, 2020
\end{tabular}

\section{Keywords:}

Causality

Order

Frequency

Genette's Narratology

\begin{abstract}
In Eka Kurniawan's novel, Lelaki Harimau, incoherent story telling is one of its most visible characteristeristic. Incohorent story telling is used by Eka kurniawan not only to pique the reader interest but also to emphasise cause and effect in every action that characters do in the novel. With a theory offered by Genette, this study tries to explain the order of event in Lelaki Harimau to show the causality that Eka Kruniawan use as the core theme in his novel. This study also tries to show how structural theories can be used as a foundation to interpret novel. From the explanation of causality in Lelaki Harimau novel, it is found that violence only begets violence.

Hal yang paling menonjol pada novel Lelaki Harimau karya Eka Kurniawan adalah ketidak runtutan dalam penceritaannya. Ketidakruntutan yang dihadirkan oleh Eka Kurniawan digunakan tidak hanya untuk memikat pembacanya tetapi juga memberikan penekanan mengenai adanya hubungan sebab-akibat disetiap tindakan tokoh di dalam novel tersebut. Melalui teori yang ditawarkan oleh Gennete, penelitian ini mencoba memaparkan secara rinci urutan-urutan peristiwa atau order di dalam novel Lelaki Harimau untuk menunjukkan kausalitas yang menjadi salah satu tema utama yang diangkat oleh Eka Kurniawan. Penelitian ini juga mencoba untuk menunjukkan bagaimana teori-teori yang bersifat strukturalis bisa dimanfaatkan untuk menjadi dasar pemaknaan terhadap novel. Dari pemaparan mengenai kausalitas di dalam novel Lelaki Harimau ditemukan bahwa kekerasankekerasan yang diterima oleh seseorang hanya akan melahirkan kekeresan pula.
\end{abstract}

\section{Corresponding Author:}

Ibnu Yustiya Ramadhan,

Program Studi S2 Kajian Sastra dan Budaya, Pascasarjana Universitas Airlangga,

Jl. Airlangga no 4-6, kec. Gubeng, kota Surabaya, Jawa Timur, Indonesia

Email: ibnu.yustiya.ramadhan-2018@fib.unair.ac.id

\section{PENDAHULUAN}

Ketika membaca novel Lelaki Harimau karya Eka Kurniawan hal yang paling menonjol yang bisa dilihat oleh pembacanya mungkin adalah bagaimana novel ini bercerita dengan urutan yang tidak runtun. Di bab pertama novel ini pembaca langsung disuguhkan dengan peristiwa pembunuhan beserta informasi siapa yang menjadi pelaku dan siapa korban pembunuhan tersebut. Detail lain dalam bab tersebut hanyalah bagaimana tokoh utama, yang juga merupakan pelaku pembunuhan, dipandang oleh tokoh-tokoh lain yang mengenalnya beserta rasa terkejut mereka akan kejadian tersebut. Setelah itu pembaca akan dibawa oleh buku ini ke peristiwa-peristiwa yang terjadi di kehidupan berbagai tokoh di masa lalu secara tidak runtun yang pada akhirnya akan menjawab berbagai 
pertanyaan yang mungkin muncul di benak pembaca setelah menyelesaikan bab pertama novel Lelaki Harimau.

Penyampain cerita yang tidak runtun bukanlah sesuatu yang asing di novel-novel sekarang. Ketidakruntutan cerita sangat biasa ditemukan, seperti pada novel-novel detektif yang selalu diawali dengan kasus pembunuhan namun penjelasan-penjelasan mengenai kejahatan tersebut biasanya dimunculkan di bab-bab berikutnya dan tidak disajikan secara runtun. Penyampain cerita yang tidak runtun tersebut biasanya membuat rasa penasaran para pembaca muncul (Guilemette \& Lévesque, 2016), dan pada akhirnya mendorong mereka untuk membaca dan memahami peristiwa-peristiwa yang terjadi agar bisa menarik kesimpulan dan pemahaman mengapa seorang tokoh bisa melakukan tindakan-tindakan tertentu.

Ketidakruntutan yang ditemukan dalam novel Lelaki Harimau sepertinya dimunculkan dengan alasan yang alasan yang telah disebutkan di atas. Pembaca akan dibuat terheranheran dan ditinggalkan dengan banyak pertanyaan ketika membaca bab pertama. Pembaca tidak memiliki informasi yang cukup tentang tokoh utama, Margio, untuk bisa memahami mengapa dia membunuh Anwar Sadat. Atau bahkan pembaca tidak mengetahui siapa sebenarnya tokoh utama di dalam novel ini ketika membaca bab pertamanya. Kurangnya informasi tersebut akan menarik minat pembaca untuk terus membaca bab-bab selanjutnya agar memiliki pemahaman penuh atas segala peristiwa yang terjadi pada bab pertama novel. Selain itu, yang menarik dari novel ini adalah bagaimana caranya dalam memberikan jawaban tersebut. Pembaca tidak secara serta merta mendapatkan penjelasan mengenai peristiwa di bab pertama di bab-bab selanjutnya tetapi diajak untuk menarik kesimpulan dan memahami peristiwa pada bab pertama melalui peristiwa-peristiwa lain yang diceritakan secara tidak runtun dan terkadang tidak memiliki hubungan yang jelas dengan peristiwa yang diceritakan sebelumnya. Peristiwa-peristiwa di masa lalu yang diceritakan di dalam novel bisa dijadikan sebagai acuan untuk memahami mengapa tokoh melakukan berbagai tindakan yang dilakukannya di masa sekarang. Dengan kata lain pembaca diajak untuk mencari hubungan sebab-akibat di dalam novel ini, dan hal tersebut menjadi salah satu karakteristik terkuat yang menarik pada novel Lelaki Harimau.

Suatu fenomena tidak mungkin terjadi tanpa diakibatkan oleh fenomena lain dan tidak mungkin pula tidak menimbulkan fenomena yang lain (Spirkin, 1983). Pernyataan tersebut merupakan sebuah konsep yang disebut sebagai kausalitas. Kausalitas pada intinya merupakan cara berpikir yang menunjukkan kemestian rasional hubungan sebab akibat (Salehnur, 2014). Dapat dikatakan kausalitas merupakan salah satu cara berpikir yang disajikan dalam novel Lelaki Harimau. Setiap peristiwa masa lalu yang diceritakan akan memiliki hubungan dengan peristiwa di masa sekarang, menjadi pemicu, alasan, serta sebab atas tindakan tokoh-tokoh. Tugas pembaca adalah memahami bagaimana peristiwa-peristiwa tersebut mempengaruhi tindakan tokoh-tokoh di dalam novel, bagaimana sebuah peristiwa bisa menjadi sebab dari rentetan peristiwa lainnya. Dengan demikian hubungan sebab-akibat, yang setelah ini akan disebut sebagai kausalitas, merupakan senjata utama dari novel Lelaki Harimau untuk menarik minat pembacanya agar membaca sampai habis dan tuntas bahkan jika perlu lebih dari satu kali agar pembaca benar-benar memahami setiap peristiwa di dalam novel ini.

Gaya penceritaan yang tidak runtun dan tema kausalitas yang begitu ditonjolkan oleh Eka Kurniawan di dalam novel Lelaki Harimau ini membuat banyak penelitian dilakukan terhadap isinya. Seperti penelitian yang dilakukan oleh Wijayanti dkk (2018) yang memanfaatkan perspektif feminis dalam membaca karya ini untuk menjelaskan dominasi laki-laki terhadap perempuan dalam kehidupan seksual. Penelitian lain terhadap novel ini juga memfokuskan kepada kekerasan yang dilakukan kepada tokoh perempuan melalui pembacaan heuristik (Prasetyo \& Haryadi, 2017). Penelitian lainnya berfokus kepada konflik batin tokoh utama di dalam novel melalui pendekatan yang strukturalis, yakni 
melalui identifikasi unsur-unsur intrinsik novel seperti alur, tokoh dan penokohan untuk merumuskan konflik batin yang terjadi pada diri tokoh dan faktor-faktor penyebabnya (Noviyanti \& Dermawan, 2018).

Gaya penceritaan Eka Kurniawan yang berfokus pada keunikan alur disetiap karyanya membuat penelitian terhadap novel lainnya, Seperti Dendam Rindu Harus Dibayar Tuntas, dilakukan oleh Ambarwati (2018). Pada penelitian tersebut alur tidak runtun yang disajikan oleh Eka Kurniawan dijadikan sebagai fokus utama penelitian yang ditumkan pula kausalitas yang kuat pada karya tersebut. Di sisi lain, penelitian mengenai kausalitas di dalam novel juga pernah dilakukan oleh Mandala, Martono, \& Seli (2014) pada penelitian mereka terhadap novel Saya Nujood, Usia 10 Dan Janda yang menunjukkan kausalitas pada konflik-konflik yang dialami oleh tokoh. Sulistiyana (2013) juga menemukan kausalitas yang memunculkan representasi kemiskinan di dalam novel Jatisaba yang menjadi objek penelitiannya,

Menemukan kausalitas di dalam novel Lelaki Harimau tentu saja bisa dilakukan melalui pembacaan yang seksama terhadap novel, namun untuk menunjukkan dan menjelaskannya secara detail teori-teori naratologi yang bersifat struktural perlu dimanfaatkan. Salah satunya adalah dengan menggunakan naratologi milik Genette. Teori Genette sendiri sudah pernah digunakan oleh penelitian lain untuk menjelaskan isi sebuah karya seperti yang dilakukan oleh Didipu (2018), Sa'adah (2018), dan Ernanda (2018). Ketiga penelitian tersebut memanfaatkan teori milik Genette untuk memaparkan pemaknaan atau nilai-nilai yang dihadirkan di dalam sebuah karya.

\section{TEORI DAN METODOLOGI}

Pada teori yang ditawarkan oleh Genette ada satu aspek analisis yang bisa membantu untuk menunjukkan kausalitas yang terdapat pada novel Lelaki Harimau yakni analisis terhadap tata cerita. Order atau tatanan merupakan analisis terhadap hubungan antar peristiwa, disebut juga sekuen, dan urutan penyajiannya di dalam narasi (Guilemette \& Lévesque, 2016). Dalam bukunya, Genette (1980) menjelaskan bahwa di dalam sebuah narasi ada dualitas waktu atas peristiwa di dalam cerita. Sebuah peristiwa di dalam cerita memiliki waktu yang sebenarnya atau waktu cerita, peristiwa dilihat berdasarkan urutan yang seharusnya terjadi pada cerita, dan waktu yang semu atau waktu naratif, peristiwa dilihat berdasarkan urutan penyajiannya di dalam narasi. Dengan menunjukkan waktu sebenarnya dan waktu semu sebuah peristiwa, hubungan antara peristiwa-peristiwa tersebut dapat ditunjukkan dengan mengaitkan tatanan waktu antar peristiwa. Aspek lain yang bisa membantu dalam pemaknaan peristiwa pada novel ini adalah frekuensi, seberapa banyak sebuah peristiwa di cerita terjadi atau disebutkan (Guilemette \& Lévesque, 2016). Melalui analisis yang ditawarkan oleh Genette ini kausalitas pada novel Lelaki Harimau yang begitu kental bisa ditunjukkan.

Peneltian ini merupakan penelitian deskriptif kualitatif. Data yang digunakan bersumber dari novel Lelaki Harimau karya Eka Kurniawan. Dalam melakukan analisis penelitian ini memanfaatkan teori struktural Gerard Genette dengan menggunakan aspek urutan (order) dan frekuensi. Urutan pada novel akan diidentifikasi terlebih dahulu dengan cara menentukan dan mengurutkan sekuen-sekuen yang ada. Setelah urutan telah diidentifikasi, frekuensi peristiwa akan dinalasis. Melalui dua tahapan tersebut akan dilakukan pembahasan untuk menjelaskan pemaknaan terhadap novel Lelaki Harimau karya Eka Kurniawan. Pemaknaan yang disampaikan akan didasarkan kepada hasil temuan data dari kegiatan identefikasi yang telah dilakukan sebelumnya agar ada dasar dari makna yang didapatkan dan disampaikan pada penelitian ini. 


\section{HASIL DAN PEMBAHASAN}

\section{Tatanan Cerita Novel Lelaki Harimau}

Agar kausalitas yang terjadi di dalam novel Lelaki Harimau bisa ditunjukkan, yang pertama perlu dilakukan adalah analisis terhadap tatanan peristiwa, yang selanjutnya akan disebut sebagai sekuen, dalam novel ini. Novel lelaki harimau memiliki waktu cerita dan waktu naratif yang tidak berjalan seiringan, disebut sebagai anachronies oleh Genette (1980), sehingga diperlukan analisis terlebih dahulu terhadap sekuen-sekuen yang ditemukan untuk melihat penempatan waktu cerita dan waktu naratif agar penarikan kesimpulan mengenai kausalitas bisa dilakukan dan dipaparkan dengan jelas dan memiliki alasan yang mendukung.

Dari penjelasan di atas maka yang pertama kali harus dilakukan adalah menentukan sekuen-sekuen di dalam novel Lelaki Harimau. Istilah sekuen digunakan karena ada pembatasan mengenai penentuan sekuan dalam cerita yang dipaparkan oleh Zaimar (1991). Batasan tersebut adalah (1) terpusat pada satu titik perhatian yang mengamati objek yang tunggal dan sama, meliputi tokoh, gagasan, maupun bidang pemikiran, (2) terjadi pada waktu dan ruang yang koheren, bisa terjadi pada waktu dan tempat tertentu atau beberapa tempat dan waktu namun masih berada pada satu tahapan yang sama, (3) dapat ditandai dengan hal-hal diluar bahasa seperti kertas kosong ditengah teks, tulisan, tata letak dalam penulisan teks, dan lain-lain. Berdasarkan batasan-batasan tersebut maka dalam novel Lelaki Harimau ditemukan sekuen-sekuen sebagai berikut.

1. Kyai Jahro memberi makan ikan di kolamnya

2. Mayor Sadrah datang dan berbincang dengan Kyai Jahro mengenai badai semalam

3. Ma Soma datang dan memberitahu bahwa Margio membunuh Anwar Sadat dengan menggigit lehernya

4. Kyai Jahro, Mayor Sadrah dan Ma Soma pergi ke tempat Anwar Sadat

5. Mayor Sadrah melihat Margio membawa pedang samurai

6. Mayor Sadrah mengambil pedang samurai yang dibawa Margio

7. Pandangan Mayor Sadrah terhadap Margio

8. Keadaan di rumah Anwar Sadat

9. Informasi mengenai siapa Anwar Sadat

10. Anwar Sadat pergi warung serabi untuk sarapan

11. Anwar Sadat menceritakan kepergian Maharani

12. Cerita tentang ketiga putri Anwar Sadat

13. Pengurusan jenazah Anwar Sadat

14. 10 menit sebelum Margio membunuh Anwar Sadat

15. Agung Yuda dan Margio

16. Pembunuhan Anwar Sadat

17. Margio ditahan di rayon militer

18. Mameh melihat harimau Margio

19. Margio bertemu dengan harimau putih

20. Perjalanan Margio ke tempat kakeknya

21. Cerita tentang harimau putih kakek Margio

22. Margio bermain dengan harimau putih

23. Margio kehilangan harimau putih

24. Margio berkata ingin membunuh ayahnya

25. Margio pergi menonton holiday sirkus

26. Margio tidur di surau

27. Kematian Mariam

28. Kemarahan Margio kepada ayahnya

29. Komar berperilalku manis

30. Margio pergi dari rumah 
31. Komar sakit keras

32. Kematian Komar

33. Tanggapan Mameh atas kematian Komar

34. Mameh melihat Komar dan Nuraeni bersetubuh

35. Komar melihat Mameh telanjang di kamar mandi

36. Mameh keluar rumah

37. Mameh memberi tahu Jafar bahwa Komar meninggal

38. Jenazah Komar diurus

39. Margio pulang

40. Jenazah Komar dibawa ke kuburan

41. Mameh menyuruh ibunya kawin

42. Nuraeni menampar Mameh

43. Perjalanan Komar dan keluarganya ke rumah 131

44. Rumah pertama Komar dan keluarganya

45. Pemilik gedong dan rumah Komar pindah

46. Komar mencari rumah baru

47. Komar mengajak dan membujuk keluarganya untuk pindah

48. Margio tidak ingin pindah

49. Komar memarahi dan memukul Margio

50. Komar dan keluarganya mmengemasi barang

51. Komar dan kelaurganya berangkat ke rumah baru mereka

52. Komar dan keluarganya sampai di rumah baru

53. Keadaan rumah baru yang remuk

54. Membersihkan rumah baru Komar dan keluarganya

55. Pemilik tanah Ma Rabiah

56. Delapan anak Ma Rabiah dan tanah warisan

57. Anak Ma Rabiah mengusir orang-orang yang tinggal di tanahnya

58. Ma Rabiah sakit hati atas tindakan anaknya

59. Ma Rabiah menjual tanahnya semurah mungkin

60. Ma Rabiah menghabiskan uang di masa tuanya

61. Ma Rabiah meninggal

62. Komar membeli tanah Ma Rabiah

63. Keluarga Komar masih tidak bahagia

64. Nuraeni berbicara dengan kompor dan panci

65. Nuraeni dianggap gila oleh keluarganya

66. Syueb melamar Nuraeni untuk menjadi istri Komar

67. Nuraeni mulai berubah menjadi seorang gadis

68. Komar pulang dari perantauan saat lebaran

69. Komar bertemu dengan Nuraeni

70. Komar pergi kencan dengan Nuraeni

71. Komar pergi merantau lagi

72. Nuraeni meminta Komar menulis surat untuknya

73. Nuraeni menunggu surat dari Komar

74. Nuraeni tidak pernah mendapatkan surat dari Komar

75. Nuraeni merasa sakit hati terhadap Komar

76. Komar pulang dari perantauan

77. Nuraeni bersifat dingin terhadap Komar

78. Nuraeni pergi ke tobong bersama Komar

79. Komar memaksa meminta ciuman Nuraeni

80. Komar pergi merantau lagi

81. Komar menikahi Nuraeni

82. Malam pertama Komar dan Nuraeni 
83. Komar dan Nuraeni pindah ke rumah pertama mereka

84. Perlakuan kasar Komar kepada Nuraeni

85. Margio lahir

86. Komar meminta cincin kawin Nuraeni untuk membeli rumah baru

87. Nuraeni mulai berbicara dengan kompor dan panci untuk menyindir Komar

88. Komar menanggapi sindiran-sindiran Nuraeni

89. Komar membeli tanah Ma Rabiah

90. Nuraeni masih berbicara dengan panci dan kompor

91. Margio jarang melihat ibunya bahagia

92. Kekerasan Komar terhadap Nuraeni yang dilihat Margio

93. Margio mulai sering menyulut emosi Komar dengan sengaja

94. Komar membuat lantai plester untuk rumahnya

95. Retakan di lantai plester muncul

96. Nuraeni merayakan kehnacuran lantai

97. Margio pergi karena tahu Nuraeni akan dipukuli oleh Komar

98. Pandangan Margio terhadap hubungan Komar dan Nuraeni

99. Komar tidak mau mengurus rumah lagi

100. Nuraeni menghiasi rumah

101. Nuareni mulai menanam bunga di pekarangan rumah

102. Pekarangan rumah Nuraeni berubah menjadi belukar bunga

103. Mameh sadar niat Nuraeni untuk memperburuk rumahnya

104. Nuraeni memetik bunga saat pemakaman Marian

105. Nuraeni tak sudi bunganya dipetik untuk pemakaman Komar

106. Margio menganggap tidak ada yang bisa membahagiakan ibunya

107. Margio melihat ibunya bahagia

108. Kehamilan Nuraeni diketahui Margio dan Mameh

109. Nuraeni sering kerja bantu-bantu di rumah Anwar Sadat

110. Margio sering diminta bekerja membantu Anwar Sadat

111. Margio dan kawan-kawan sering menonton TV di rumah Anwar Sadat

112. Margio berada sendirian di dekat jendela rumah Anwar Sadat

113. Margio diminta tolong Anwar Sadat membeli lauk

114. Margio berkenalanan dengan Maharani

115. Anwar Sadat meminta Margio membawa Nuraeni untuk membantu memasak

116. Nuraeni senang berkerja di rumah Anwar Sadat

117. Anwar Sadat mulai mendekati dan menjamahi Nuraeni

118. Nuraeni menerima tindakan Anwar Sadat dan menyukainya

119. Anwar Sadat dan Nuraeni berhubungan seks

120. Nuraeni menyadari kehamilannya

121. Perangai Nuraeni berubah menjadi lebih bahagia

122. Komar menyadari kehamilan Nuraeni

123. Komar memukuli Nuraeni

124. Margio menyadari Nuraeni hamil bukan karena Komar

125. Komar mulai memikirkan kesalahan dan kekerasan yang dilakukannya

126. Masa-masa kehamilan Nuraeni

127. Kelahiran Marian

128. Margio dan Maharani di lapangan bola

129. Masa lalu Margio dan Maharani

130. Maharani mempertanyakan perasaan Margio kepadanya

131. Kepergian Margio dari rumah

132. Margio kembali saat kematian Komar

133. Penguburan Komar

134. Margio pulang ke rumah 
135. Mameh meminta Margio memotong ayam untuk selamatan Komar

136. Margio melihat wajah dingin Nuraeni

137. Ingatan Margio tentang Marian

138. Margio melihat Nuraeni dan Anwar Sadat bersetubuh

139. Margio mengatakan kepada Maharani bahwa Anwar Sadat menghamili Nuraeni

140. Maharani pergi meninggalkan Margio

141. Margio melihat Nuraeni masih bersedih

142. Margio meminta Anwar Sadat menikahi ibunya

143. Margio membunuh Anwar Sadat

Sekuen-sekuen di atas di urutkan sesuai dengan penyajiannya di dalam novel Lelaki Harimau. Dengan kata lain urutan sekuen di atas sudah menunjukkan waktu naratif dari novel Lelaki Harimau. Sebagai cerita yang bersifat achronies maka urutan sekuen di atas perlu di tata lagi agar waktu cerita bisa dilihat. Adapun urutan waktu cerita dari novel Lelaki Harimau adalah sebagai berikut. 

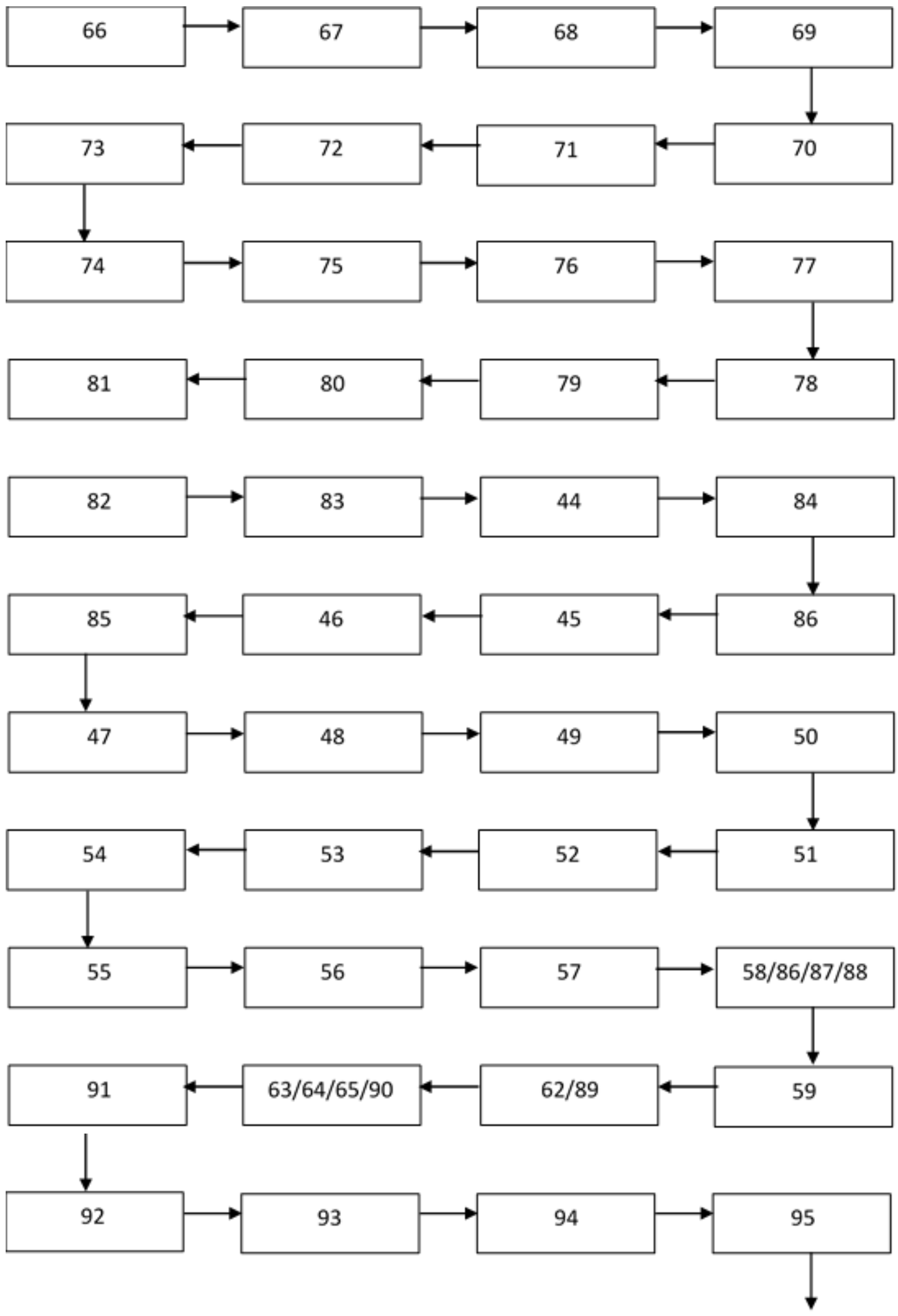


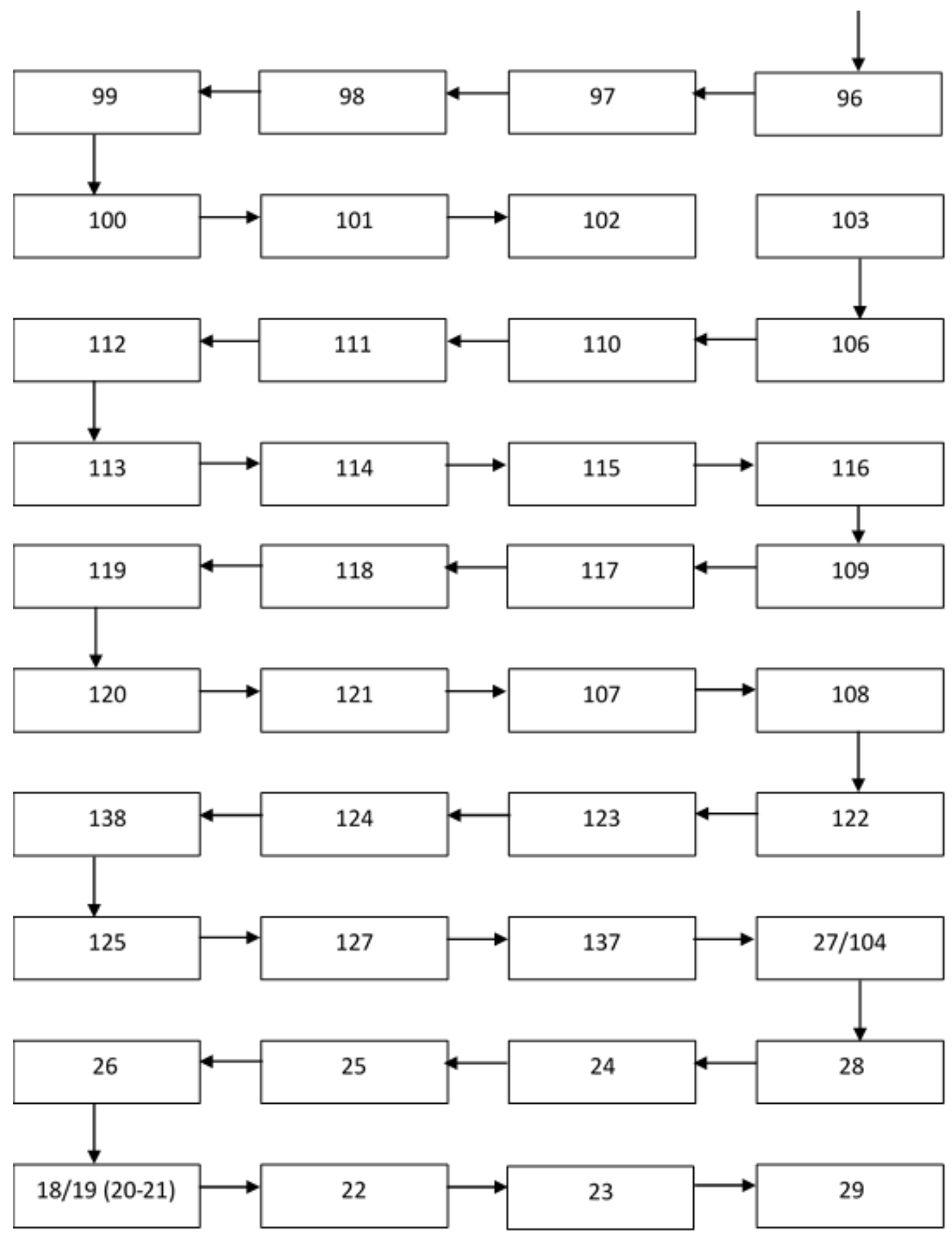




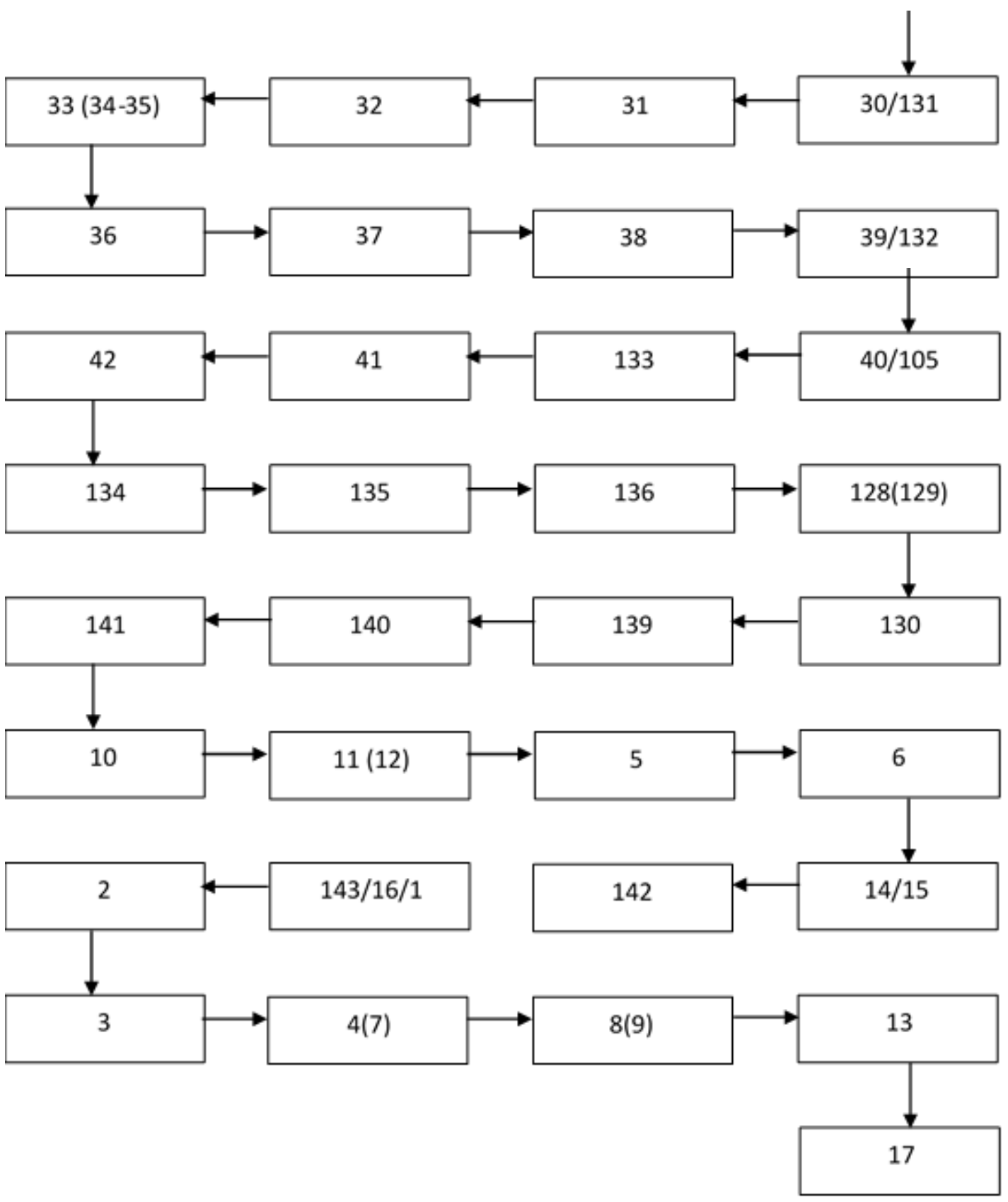

Gambar 1. Bagan urutan waktu cerita novel Lelaki Harimau

Sekuen-sekuen di atas dirutkan berdasarkan urutan cerita dari yang paling awal terjadi. Hal tersebut dilakukan agar pengurutan waktu cerita pada sekuen bisa disajikan dan dibaca dengan jelas. Oleh karena itu urutan waktu cerita diawali oleh sekuen 66 yang merupakan awal ditentukannya pertunangan antara Komar dan Nuraeni. Dari sekuen tersebut sekuen-sekuen lain pun terjadi.

Dalam pengurutan waktu cerita novel Lelaki Harimau ditemukan beberapa sekuen yang terjadi pada waktu yang bersamaan. Sekuen-sekuen tersebut dimasukkan ke dalam satu kotak waktu yang sama dan dibatasi dengan tanda garis miring (/) di dalam alur di atas. Sekuen-sekuen yang terjadi dalam waktu yang bersamaan bisa dilihat pada sekuen 143, 16, dan 1. Sekuen 143 dan 16 merupakan sekuen yang sama namun diceritakan dengan cara yang berbeda pada halaman yang berbeda. Sementara sekuen 1 secara 
eksplisit dituliskan terjadi di saat sekuen 143 dan 16 terjadi. Hal tersebut bisa dilihat dari kutipan-kutipan berikut

Ia mendekap erat Anwar Sadat, yang terkejut dan berusaha meronta, namun dekapan itu kuat di bawah lengannya, tangan Margio menjuntai ke atas merenggut rambut Anwar Sadat bikin kepalanya tak banyak kutik. Saat itulah Margio menancapkan gigi-giginya di leher kiri Anwar Sadat, seperti ciuman kekasih yang membara ke permukaan kulit di bawah telinga, mendengus dan hangat penuh nafsu, dan lelaki itu masih terpana untuk tahu apa yang diperbuat Margio.(Kurniawan, 2014: 32)

Tatapan itu jelas mencela gagasan konyol Margio. Dan kalimat selanjutnya memberi penjelasan melimpah, "Lagi pula aku tak mencintaimu ibumu."

Itulah kala harimau di dalam tubuhnya keluar. Putih serupa angsa. (Kurniawan, 2014: 190)

Senja ketika Margio membunuh Anwar Sadat, Kyai Jahro tengah masyuk dengan ikanikan di kolamnya, ditemani aroma asin yang terbang di antara batang kelapa, dan bunyi falseto laut, dan badai jinak merangkak di antara ganggang, dadap, dan semak lantana. (Kurniawan, 2014: 1)

Selain itu ada pula sekuen yang merupakan bagian sekuen lain yang berbentuk ingatan tokoh atau penjelasan dari narator. Sekuen-sekuen tersebut diletakkan di satu kotak dan diberi tanda kurung "(-)" sebagai penanda. Sebagai contoh, hubungan antara sekuen 4 dan sekuen 7. Pada sekuen 4 diceritakan bahwa tokoh Mayor Sadrah beserta Kyai Jahro dan Ma Soma segera bergegas pergi ke rumah Anwar Sadat setelah itu cerita dilanjutkan dengan sekuen 7 yang merupakan peristiwa-peristiwa di masa lalu yang ada di dalam ingatan Mayor Sadrah. Hal tersebut diperjelas oleh kalimat dalam salah satu kutipan berikut.

Anak celaka, pikir Mayor Sadrah atas ingatannya pada Margio, bukannya rehat dan bersiap untuk perburuan berikut, malahan ia pergi ke rumah Anwar Sadat dan membunuhnya, meski semua orang sering berpikir Anwar Sadat sedikit mirip dengan babi. (Kurniawan, 2014: 7)

Kalimat pikir Mayor Sadrah atas ingantannya pada Margio memberikan kejelasan bahwa sekuen 7 bukan merupakan sebuah peristiwa yang diceritakan pada waktu cerita yang lalu. Sekuen 7 bisa dianggap sebagai bagian dari salah satu sekuen lain yang sedang terjadi, dalam hal ini dianggap sebagai bagian dari sekuen 4 karena yang sedang terjadi adalah sekuen 4 .

Setelah mengurutkan sekuen-sekuen di dalam novel Lelaki Harimau melalui waktu cerita kita akan bisa melihat dan mengamati bagaimana sekuen-sekuen tersebut berjalan secara jelas. Dengan mengamati waktu cerita yang sudah runtut dari sekuen yang paling awal sampai yang paling terakhir terjadi kita bisa melihat berbagai hubungan antar sekuen tersebut. Dengan demikian penentuan hubungan sebab-akibat atau kausalitas di dalam novel Lelaki Harimau bisa dilakukan.

\section{Kausalitas di dalam Novel Lelaki Harimau}

Jika urutan waktu cerita di dalam novel Lelaki Harimau ditelaah lagi maka kita bisa melihat bahwa sekuen-sekuen yang ada menceritakan peristiwa pada beberapa tokoh. Pada novel ini cerita disampaikan oleh seorang narator yang berada di luar teks namun narator hanya menceritakan peristiwa seseuai dengan apa yang diketahui oleh karakter yang diceritakannya. Informasi yang diberikan oleh narator hanyalah informasi yang 
diketahui oleh karakter yang sedang diceritkan. Oleh karena itu pada novel Lelaki Harimau terdapat sekuen yang sebenarnya sama namun memiliki jumlah informasi yang berbeda. Jika digambarkan penceritaan yang dilakukan oleh narator di dalam novel Lelaki Harimau adalah sebagai berikut.

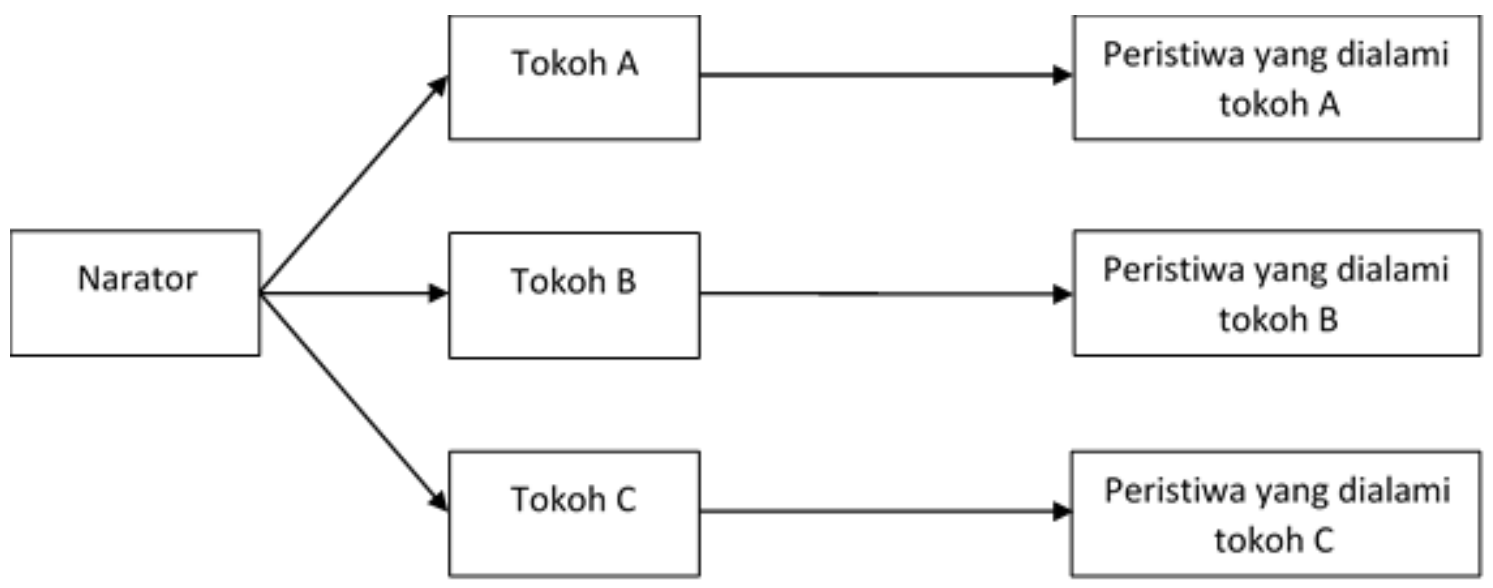

Gambar 2. Bagan penceritaan narator

Dari informasi tersebut ketika hubungan kausalitas antar sekuen di dalam novel Lelaki Harimau ingin dianalisis, analisis bisa difokuskan pada satu tokoh. Hal tersebut dikarenakan dengan memfokuskan pada satu tokoh kita bisa melihat sekuen-sekuen mana yang memiliki dampak langsung terhadap tokoh di cerita, bisa berupa sekuen yang berdampak pada cara tokoh memandang tokoh lain, tindakan yang dilakukan tokoh, dan lain-lain. Hal tersebut juga dimudahkan oleh bagaimana narator di dalam cerita menyampaikan informasi berupa ingatan tokoh tentang sekuen di masa lalu serta pendapatnya mengenai apa yang terjadi di sekuen tersebut. Dari informasi tersebut kita bisa menarik pemahaman tentang sekuen apa saja yang mempengaruhi tokoh di sekuen yang sekarang sehingga hubungan kausalitas antar sekuen bisa dicari.

Pada tokoh Margio, banyak sekuen yang diceritakan dari apa yang diketahuinya atau sekuen yang masih berhubungan dengan Margio. Selain itu, sekuen-sekuen mengenai apa yang dia pikirkan dan rasakan terhadap tokoh lain juga cukup banyak, mengingat Margio adalah tokoh utama pada novel ini. Hubungan kausalitas bisa ditemukan jika kita melihat lagi salah satu sekuen tentang Margio dan menghubungkannya dengan sekuen lain yang masih berkaitan dengan Margio. Sebagai contoh, pada sekuen 24 Margio mengatakan kalau dirinya ingin membunuh ayahnya. Sekuen ini muncul di bab kedua novel dan pembaca tidak akan mengetahui dengan jelas mengapa seorang anak sampai ingin membunuh ayahnya sendiri sebelum mengetahui sekuen-sekuen lain yang muncul di waktu naratif yang lebih jauh. Setelah dirutukan berdasarkan waktu cerita, alasan sekuen 24 bisa terjadi akhirnya menjadi jelas. Perhatikan bagan kausalitas yang berhubungan dengan sekuen 24 berikut.

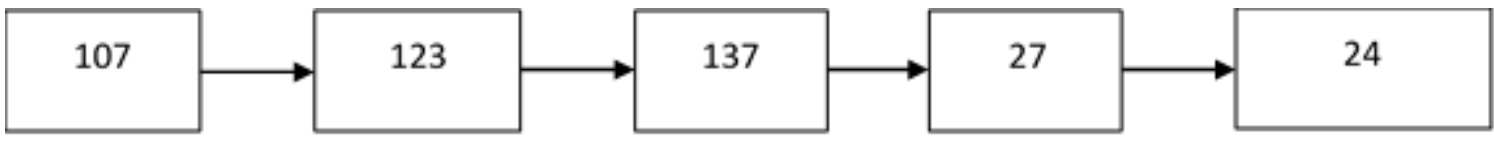

Gambar 3. Sekuan kausalitas tokoh Margio 
Bagan di atas diurutkan sesuai dengan waktu cerita dan diisi oleh sekuen yang berhubungan. Pada sekuen 107 Margio melihat ibunya yang selalu terlihat sedih menjadi bahagia. Hal tersebut merupakan hal yang sangat mengejutkan bagi Margio karena dia sendiripun tidak bisa membuat ibunya sebahagia itu. Hal tersebut bisa dilihat pada kutipan berikut.

Hingga suatu hari ia melihatnya demikian berbeda. Ia pulang ke rumah karena lapar di pagi hari selepas tidur di pos ronda yang sesaat sebab ia hampir begadang melihat pertunjukkan wayang dengan lakon Semar Papa. Ia melihat wajah ibunya lebih berseri, ia tahu pasti sebab tak pernah begitu sebelumnya, dengan rona merah yang tiba-tiba muncul di pipinya, walau tak mengembalikan kemontokan sebagaimana sering diceritakan paman-paman dan bibi-bibi. (Kurniawan, 2014: 123)

Kebahagian yang dimiliki oleh Nuraeni adalah sesuatu yang sanga berharga bagi Margio. Dia akan rela melakukan apa saja agar bisa menjaga kebahagiaan milik ibunya tersebut. Hal tersebut dikarenakan sudah terlalu lama dia melihat ibunya bersedih. Keinginan Margio untuk selalu menjaga kebahagian ibunya bisa dilihat pada kutipan berikut.

Bahkan jika pun belukar bunganya bikin ia bahagia, kebahagiaan itu sedikit saja. Dan demi yang sedikit itulah Margio selalu menjaga pekarangan rumah tak rusak dari kesemrawutannya, sejauh ia pikir demikianlah yang dikehendaki ibunya. (Kurniawan, 2014: 123)

Bagi Margio satu-satunya orang yang bisa menghanncurkan kebahagian Nuraeni yang jarang dia lihat adalah Komar, ayahnya sendiri. Margio sejak kecil sudah melihat dan merasakan pula perlakuan kasar Komar terhadap Nuraeni dan juga dirinya. Dia menganggap kesedihan yang selalu muncul di ibunya disebabkan oleh ayahnya tersebut. Bahkan ketika ibunya tengah bahagia karena sedang hamil Margio melihat perlakuan kasar yang dilakukan oleh Komar kepada ibunya. Hal tersebut bisa dilihat pada sekuen 123 dimana Komar selalu mengasari Nuraeni namun tetap bisa mejaga rasa bahagianya. Perlakuan Komar terhadap Nuraeni yang sedang hamil tersebut akhirnya semakin membakar rasa benci yang dimiliki Margio kepada Komar.

Di sekuen 137 diceritakan bagaimana Margio mengingat hidup Marian yang hanya berumur seminggu penuh dengan kesengsaraan. Marian dilahirkan dengan tubuh yang kecil. Kelahiran Marian mungkin mampu memberikan rasa bahagia kepada Nuraeni yang selalu diinginkan oleh Margio namun melihat kenyataan bahwa Marian mungkin tidak bisa bertahan hidup membuat kebahagian tersebut berangsur-angsur pudar. Keadaan Marian yang begitu menyedihkan tersebut tidak dihiraukan oleh Komar dan itu membuat Margio semakin memiliki amarah yang besar kepada Komar. Hal tersebut bisa dilihat dari kutipan berikut.

Margio tak sanggup meliha tamasya tersebut, baik si bayi maupun ibunya, sebab ia pun tak mampu mengusir rasa cemas tersebut, dan pilih meninggalkan kamar menghindari menyaksikan proses kematian dan kejatuhan mendalam seorang ibu yang sedih.

Sepanjang hari itu Komar bin Syueb masih juga belum pulang, dan ingin benar Margio memenggal kepalanya. (Kurniawan, 2014: 173)

Di sekuen 27 yang menceritakan tentang kematian Marian, perilaku Komar yang tidak peduli masih tetap dilihat oleh Margio. Hal tersebut akhirnya benar-benar membuat dia lepas kendali karena kemarahan yang sudah begitu memuncak. Hal tersebut bisa dilihat pada kutipan berikut. 
Komar bin Syueb pulang tak lama setelah mereka menguburkan Marian subuh-subuh, tanpa dosa dan bengis di wajah.... Ia menampilkan dirinya sebagai lelaki udzur setengah mampus yang tanpa kendali rasa apa pun, masuk rumah duka sekonyong dan tak juga bertanya apa yang sedang kalian sedihkan, sebab betul tampaknya ia sendiri tahu kematian Marian dan itulah yang menyeretnya pulang untuk merayakannya, duduk di dapur dan memakan ayam sisa selamatan tak ada malu, dan tidur mendengkur penuh kekejian. Hingga kemudian, tak tahan oleh kelakuan tanpa aling-aling, Margio meraih panci dan satu-satunya panci yang mereka miliki, membantingkan ke lantai menimbulkan ledakan heboh yang tentu membangunkan Komar bin Syueb. (Kurniawan, 2014: 56-57)

Berdasarkan sekuen-sekuen yang sudah dibahas di atas maka bisa dilihat bahwa sekuen 24 bisa terjadi karena peristiwa-peristiwa yang terjadi di sekuen-sekuen yang terjadi lebih dahulu jika dilihat dari urutan waktu cerita. Peristiwa-peristiwa di sekuensekuen sebelumnya terus membuat Margio memiliki rasa benci terhadap Komar. Hal tersebut menyebabkan Margio sering mengucapkan bahwa dia ingin membunuh ayahnya seperti pada sekuen 24. Dari penjelasan di atas kita bisa melihat bahwa kausalitas itu ada di dalam novel Lelaki Harimau. Kausalitas-kausalitas tersebut ditebarkan oleh Eka Kurniawan di berbagai bab dan tugas pembacalah untuk menemukan dan menghubungkannya.

\section{Kekerasan yang Melahirkan Kekerasan dalam Novel Lelaki Harimau}

Setelah sekuen-sekuen di dalam novel Lelaki Harimau dapat diamati dengan jelas hingga ditemukan hubungan antar sekuen yang merupakan kausalitas, maka pemaknaan lebih lanjut dapat dilakukan berdasarkan temuan-temuan tersebut. Dengan sekuensekuen yang terlihat dengan jelas dapat diamati peristiwa apa yang sering dimunculkan di dalam novel Lelaki Harimau, disebut juga frekuensi. Melalui frekuensi peristiwa pada cerita pemaknaan bisa dilakukan karena frekuensi melihat hubungan antara seberapa sering sebuah peristiwa terjadi atau disebutkan di dalam cerita (Guillemette \& Lévesque, 2016).

Berdasarkan sekuen-sekuen yang telah maka pada novel Lelaki Harimau banyak ditemukan sekuen dengan frekuensi yang bersifat Singulative, dimana peristiwa yang terjadi disebutkan hanya sekali (Guerlac, Genette, \& Lewin, 1980). Di dalam novel Lelaki Harimau banyak sekuen yang menceritakan suatu peristiwa yang terjadi hanya sekali baik di masa sekarang atau di masa lalu. Seperti pada sekuen 66 sampai dengan 81 yang menceritkan bagaimana Komar dan Nuraeni bertemu hingga menikah.

Melalui peristiwa yang sifatnya hanya terjadi sekali tersebut Eka Kurniawan ingin memperjelas pesan apa yang ingin disampaikannya. Pada sekuen-sekuen yang memiliki frekuensi singulative sebagian besar menceritakan tentang kekerasan-kekerasan yang dilakukan oleh tokoh-tokoh, seperti pada sekuen 49, 94, dan 123 yang menceritakan kekerasan yang dilakukan oleh Komar. Melalui sekuen-sekuen tersebut dapat dikatakan Eka Kurniawan ingin memperjelas bahwa ada tema kekerasan yang diangkat di dalam novelnya. Lebih lanjut, ketika sekuen-sekuen tersebut diurutkan dan kemudian dihubungkan ditemukan bahwa ada kausalitas diantara sekuen-sekuen tersebut. Seperti pada sekuen 143 dan 16, pembunuhan Anwar Sadat yang dilakukan oleh Margio, yang terjadi karena kecintaan Margio terhadap ibunya yang sering diperlakukan secara kasar oleh Komar sehingga sangat jarang merasa bahagia. Ketika Anwar Sadat mengatakan dia tidak mencintai ibunya Margio merasa sangat marah sehingga dia membunuh Anwar Sadat.

Dari penjelasan di atas dapat dilihat bahwa salah satu tema dari novel Lelaki Harimau yang bisa disimpulkan berdasarkan kajian terhadap struktur narasinya adalah bagaimana kekerasan-kekerasan yang dilakukan tokoh dapat menghasilkan kekerasan-kekerasan 
yang dilakukan oleh tokoh yang lain. Kekerasan yang dilakukan oleh Komar membuat Margio pada akhirnya membunuh Anwar Sadat. Melalui sekuen-sekuen cerita yang penuh dengan kekerasan dan saling memiliki hubungan kausalitas Eka Kurniawan menggambarkan kekerasan yang melahirkan kekerasan tersebut di dalam novelnya.

\section{SIMPULAN}

Lelaki Harimau merupakan novel dengan gaya penceritaan yang tidak runtun. Ketidakruntutan tersebut sengaja dibuat selain untuk meminat pembacanya juga untuk memberikan kejelasan mengenai pesan apa yang ingin disampaikan. Melalui penelitian ini ketidakruntutan pada novel dianalisis dengan mengidentifikasi sekuen-sekuen yang terdapat didalam novel sehingga menghasilkan runtutan cerita yang jelas. Melalui keruntutan cerita tersebut ditemukan bahwa setiap bagian memiliki hubungan sebabakibat atau kausalitas di dalamnya. Selain itu, dengan urutan cerita yang sudah jelas frekuensi yang paling banyak digunakan juga bisa ditemukan. Pada novel Lelaki Harimau frekuensi singulative banyak ditemukan pada sekuen, ditunjukkan dengan banyaknya peristiwa yang diceritakan hanya sekali. Frekuensi yang bersifat singulative membuat pesan yang ingin disampaikan oleh Eka Kurniawan bisa terlihat dengan jelas. Peristiwaperistiwa yang terjadi kebanyakan menceritakan tentang kekerasan yang dilakukan oleh tokoh dan frekuensi yang bersifat singulative membantu memperjelasnya. Sekuen-sekuen singulative yang sebagian besar berisi tentang kekerasan dan memiliki hubungan kausalitas dengan sekuen lain yang juga berisi kekerasan membuat penelitian ini menyimpulkan bahwa Eka Kurniawan ingin menggambarkan bagaimana kekerasan hanya akan melahirkan kekerasan di dalam novel ini.

Salah satu tujuan dari penelitian ini adalah untuk menunjukkan bagaimana sebuah teori struktural seperti naratif milik Genette bisa digunakan dalam melakukan pemaknaan pada sebuah karya sastra. Pada pengaplikasiannya tentu saja sangat dimungkinkan akan memiliki pemaknaan yang berbeda karena sifat pemaknaan sastra yang subjektif. Oleh karena itu, peniliti menyarankan untuk peneliti selanjutnya yang ingin menggunakan struktural naratif Genette untuk bisa memberikan penjelasan mengenai pemaknannya melalui temuan-temuan dari unsur-unsur naratif di dalam teks berdasarkan teori yang ditawarkan oleh Genette. Selain itu, teori struktural tentunya juga memiliki kekurangan dalam menjelaskan pemaknaan yang lebih mendalam karena hanya didasari dengan apa yang ada di dalam teks. Oleh karena itu, peneliti juga menyarakan kepada peneliti lain untuk memadukan teori struktural ini dengan teori-teori pos-struktural yang bisa membantu penjelasan terhadap pemaknaan yang lebih mendalam.

\section{REFERENSI}

Ambarwati, L. (2018). Novel Seperti Dendam Rindu Harus Dibayar Tuntas Karya Eka Kurniawan: Analisis Alur (Doctoral dissertation, Universitas Gadjah Mada).

Chichik Try Wijayanti, Panji Kuncoro Hadi, Y. F. (2018). Dominasi laki-laki atas perempuan terhadap kehidupan seksual dalam novel lelaki harimau karya eka kurniawan. Widyabastra.

Didipu, H. (2018). Struktur naratif novel Osakat Anak Asmat Karya Ani Sekarningsih (Perspektif naratologi Gard Genette). AKSARA: Jurnal Bahasa Dan Sastra. https://doi.org/10.23960/aksara/v19i1.pp15-27

Ernanda, F. (2018). Nasionalisme dalam film 3 Srikandi karya Imam Brotoseno (kajian naratologi Gerard Genette). BAPALA, 5(2).

Guerlac, S., Genette, G., \& Lewin, J. E. (1980). Narrative discourse, an essay in method. MLN. https://doi.org/10.2307/2906507 
Guillemette, L., \& Lévesque, C. (2016). Narratology. Retrieved from http://www.signosemio.com/genette/narratology.asp.

Kurniawan, E. (2014). Lelaki Harimau. Jakarta: Gramedia.

Noviyanti, P. B., \& Dermawan, R. N. (2018). Konflik batin tokoh utama pada Novel Lelaki Harimau Karya Eka Kurniawan: pendekatan psikologi sastra. CARAKA, 5(1), 174196.

Prasetyo, Y., \& Haryadi, H. (2017). Kekerasan terhadap tokoh perempuan dalam Novel Seperti Dendam Rindu Harus Dibayar Tuntas dan Lelaki Harimau Karya Eka Kurniawan. Seloka: Jurnal Pendidikan Bahasa Dan Sastra Indonesia, 6(2), 152-160.

Salehnur, S. (2014). Kausalitas. Jurnal Ushuluddin, (Vol 22, No 2 (2014): Juli-Desember), 224-238. Retrieved from http://ejournal.uinsuska.ac.id/index.php/ushuludin/article/view/738

Seli H. Martono; Mandala, Weni, S. (2014). Kausalitas konflik tokoh utama novel saya nujood, usia 10 dan janda. Jurnal Pendidikan Dan Pembelajaran, (Vol 3, No 4 (2014): April 2014). Retrieved from http://jurnal.untan.ac.id/index.php/jpdpb/article/view/5395

Spirkin, A. (1983). Dialectical materialism. Moscow: Progress Publisher.

Sufi Ikrima Sa'adah. (2018). Kajian naratologi Genette Dalam Tiga Cerita Pendek Pilihan Kompas Tahun 2000an. BASINDO : Jurnal Kajian Bahasa, Sastra Indonesia, Dan Pembelajarannya. https://doi.org/http://dx.doi.org/10.17977/um007v2i22018p119

Sulistiyana, P. (2013). Representasi kemiskinan dalam novel Jatisaba karya Ramayda Akmal (kajian sosiologi sastra). Bahtera Sastra: Antologi Bahasa dan Sastra Indonesia, 1(3).

Zaimar, O. K. S. (1991). Menulusuri makna ziarah Karya Iwan Simatupang. Jakarta: Intermassa. 